\title{
Medievalista
}

Online

23 | 2018

Número 23

\section{"Mulier ne debuerit habere regnum": a regência na menoridade de D. Afonso V vista pelos juristas}

"Mulier ne debuerit habere regnum": the regency during D. Afonso V minority seen by lawyers

\section{Manuel Francisco Ramos}

\section{OpenEdition}

\section{Journals}

\section{Edição electrónica}

URL: http://journals.openedition.org/medievalista/1664

DOI: 10.4000/medievalista.1664

ISSN: $1646-740 X$

\section{Editora}

Instituto de Estudos Medievais - FCSH-UNL

\section{Edição impressa}

Data de publição: 1 Janeiro 2018

\section{Refêrencia eletrónica}

Manuel Francisco Ramos, «"Mulier ne debuerit habere regnum": a regência na menoridade de D. Afonso V vista pelos juristas », Medievalista [Online], 23 | 2018, posto online no dia 07 maio 2018 , consultado no dia 06 maio 2019. URL : http://journals.openedition.org/medievalista/1664 ; DOI : 10.4000/medievalista.1664

Este documento foi criado de forma automática no dia 6 Maio 2019

(C) IEM 


\section{"Mulier ne debuerit habere regnum": a regência na menoridade de D. Afonso V vista pelos juristas}

"Mulier ne debuerit habere regnum": the regency during D. Afonso V minority seen by lawyers

Manuel Francisco Ramos

\section{NOTA DO EDITOR}

Data recepção do artigo / Received for publication: 16-03-2017

Data aceitação do artigo / Accepted in revised form: 20-10-2017

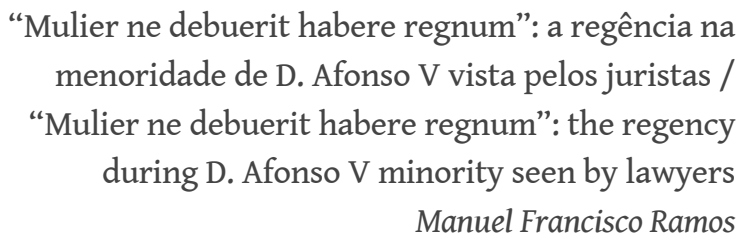

1.

Com a morte prematura de D. Duarte [9/9/1438], o herdeiro do trono, Afonso, de quase sete anos, foi alevantado rei, mas não pôde governar por não ter róbora, i.e., não ter atingido a idade da razão. Em Portugal, a maioridade régia era adquirida aos 14 anos, como preceituavam os "foro(s) d'Espanha"1 e não aos 25 (ou então aos 20 anos $^{2}$ ), como determinava o direito justinianeu, situação que tem paralelo com as Partidas II, 15, 3. Assim sendo, teria de ser nomeado um regente que assegurasse a administração do reino na menoridade do rei, isto é, de 1438 a pelo menos 1446. 
2 Era a quinta vez na história de Portugal que o instituto da regência era posto em prática e a terceira relativa a uma mulher: depois de D. Teresa, isto no caso de se aceitar como autêntica regência a acção governativa da mãe de D. Afonso Henriques³; de D. Afonso, conde de Bolonha, até à morte de Sancho II [1245-1247], com o título de "visitador, procurador e defensor do reino"; da rainha D. Leonor Teles de Meneses, a qual entre 1383-1384, após a morte de D. Fernando, exerceu nominalmente a regência em nome de sua filha, D. Beatriz, então de 10 anos e casada com o rei de Castela, D. Juan I ${ }^{4}$; e do Mestre de Avis, igualmente após a morte de D. Fernando. Também há situações de co-regência ${ }^{5}$; também há regências por o rei se ter ausentado do reino ${ }^{6}$.

3 Mas quem deveria ser o contemplado, se não havia legislação nacional sobre regências dos monarcas - as Cortes de Lamego de 1143, que alegadamente regulavam a sucessão dinástica de Portiugal, nunca existiram nem nunca foram convocadas, são antes uma falsificação patriótica do séc. XVII ${ }^{7}$ - e os costumes do reino nenhuma resolução segura autorizavam por haver mais do que uma tradição? O melhor a fazer naquele momento era abrir o testamento do falecido rei, ver as suas cláusulas e esperar que elas elucidassem a corte e os representantes dos três estados acerca da questão. Talvez D. Pedro, filho secundogénito e, por morte de D. Duarte, o mais velho dos filhos de D. João I, tivesse grande esperança em figurar no testamento, se não na posse plena da regência pelo menos com uma parte substancial. Aliás, já no passado ele havia sido nomeado por D. Duarte curador do herdeiro do trono, D. Afonso, juntamente com o irmão Henrique. Foi nas cortes de Leiria-Santarém [11 de novembro de 1433], pouco depois de D. Duarte ter sido entronizado rei, "para receberem em seu nome os preitos, homenagens e juramentos de lealdade dos três estados"8. Por isso, as expectativas deviam ser grandes.

4 Todavia, aberto o testamento do falecido rei, o qual não se conserva, foi nele achado que a regência do reino ficaria a cargo da rainha D. Leonor in solido, juntamente com a tutela e a curatela do filho menor; também seria a herdeira dos bens móveis de D. Duarte. Uma Carta de Crença enviada pelos vencedores de Alfarrobeira a D. João II de Castela e ao ducado da Borgonha, após a morte de D. Pedro, em Alfarrobeira, e que em grande parte é uma caricatura da figura do Infante, resume desta forma os eventos desse tempo":

"por morte delrrej, meu senhor e padre [D. Duarte], que Deos haja, fiquamos de idade de sete annos. E porque no seu solene testamento, que logo no dia seguinte [10 de setembro de 1438], a requerimento de todolos tres estados, foy aberto e pruuicado, se continha que a rrajnha, minha senhora e madre [D. Leonor de Aragão], de piadosa lembrança, como nossa titor, nos criasse e tiuesse regimento e aministração comprida de todas nossas cousas"10.

5 Isso significava que, passados cinco anos, D. Duarte tinha mudado de ideias e que não queria que os seus irmãos tivessem qualquer participação na tutela do reino e na tutela e curatela do rei, mas unicamente sua mulher. E porque seria? Desconfiava das ambições desmedidas de D. Pedro e de que ele, experimentado como era, não devolvesse o poder ao sobrinho? Apesar de mãe de várias crianças, tinha plena confiança na sua mulher, acerca da qual afirma a Crónica de D. Afonso $V^{11}$ que era "muyto honesta, virtuosa, prudente, devota e muyto amiga da vyda e honra d'elRey seu Marido"? Tem sido referido que o que D. Duarte pretende é que o poder fique na pessoa mais próxima dele e do filho primogénito; e que é normal que se sirva da esposa para deixar algo aos filhos ${ }^{12}$. Poderá ser, mas importa ter presente as questões jurídicas acerca desta questão, coisa que nos propomos fazer e que é relevante. No dia seguinte ao falecimento do rei (10/09/1438), os infantes de Avis, a nobreza, prelados e povo, parecendo aceitar as disposições testamentárias do falecido rei, juraram e prometeram executar as suas cláusulas, até 
porque, segundo os vencedores de Alfarrobeira - em que pontificava o duque de Bragança, D. Afonso, e seus filhos como entidades maiores -, ele tinha sido completamente redigido de acordo com o direito. Afirma a Carta de Crença, que de novo citamos:

"os jfantes dom Pedro e dom Amrique, meus tios, e os condes, prelados, fidalgos e pouos que presentes erão o tiuerão por bem, jurando e prometendo primejro os ditos meus tios, desy todos os outros de o ter e manter, porque concordaua com as leis imperiaes, que outorguarão as titorias dos filhos as viuuas e onestas madres, e com os foros dEspanha e antiguas vsanças e ordenações, praticadas em nossos rrejnos"13.

6 Nesse mesmo dia 10 de setembro, D. Pedro dirigiu a sessão do alevantamento do rei e, no decorrer dela, sugeriu que D. Fernando, filho secundogénito de D. Duarte (tal como D. Pedro é filho secundogénito de D. João I), de cinco anos, fosse imediatamente jurado herdeiro e sucessor do trono, o qual passou a intitular-se "príncipe", aliás o primeiro, porque todos os anteriores filhos segundos foram "infantes". Por conseguinte, a sucessão de D. Afonso V nunca foi posta em causa, nem que D. Fernando seria o herdeiro em caso de morte de Afonso; nem que D. Pedro seria o rei em caso de morte dos dois irmãos; o problema, como a seguir se verá, é de regência, por não haver uma lei da sucessão e da regência que esclarecesse a situação, mas apenas ideias nascentes, ideias em crise e ideias em conflito.

7 Nessa altura, vários conselheiros do reino - é Rui de Pina que o lembra ${ }^{14}$ - alertaram a rainha viúva para a dificuldade da tarefa, quer por ser trabalho exigente, quer por ter a seu cargo vários filhos: Afonso, Fernando, Leonor, Catarina e no ventre Joana, que viria a nascer nos finais de março de 1439. Também a alertaram para o facto de os príncipes de Avis terem uma palavra a dizer em matéria de governação e ainda para a aversão que havia no reino às rainhas estrangeiras, sobretudo quando assumiam funções governativas. Além disso, cinco anos antes, Pedro e Henrique tinham sido nomeados temporariamente curadores e era provável que agora quisessem ser mais do que isso. Ela deve ter percebido bem a dificuldade da missão, mas não anuiu aos conselhos, começando "logo a husar do Regimento ynteiramente sem alguma pubryca contradyçam" ${ }^{15}$, não só porque julgasse que a lei estava do seu lado, mas também porque era essa a vontade do seu falecido esposo e ainda porque, gozando do apoio da nobreza senhorial, se sentisse confiante no desempenho do cargo de regente.

8 Pouco depois de iniciada a regência e assumido a tutoria do rei menor, apoiada na legalidade do testamento de D. Duarte, a sua autoridade - tal como havia sido previsto pelos conselheiros - foi contestada por D. Pedro e partidários, que a Crónica resume assim: "agora pellas praças se solta, que ElRey nosso Senhor, vosso Marido, que Santa Gloria aja, vos nam podia leixar este cargo de reger: cá este poder demleger Regedor do Reino era somente ao Reino, e aos tres Estados dele resservado"16; mas que a Carta de Crença atribui à "desordenada cobiça" de D. Pedro, a qual, por ser patológica, o destrói moralmente: "hum mujto agudo e desordenado dezejo de reger estes rrejnos, por qualquer arte ou industria que podesce, o qual dezejo trazia escondido sob aquellas falças cerimonias de fengida obediençia, do que os auizados homens, dando lugar aos tempos, usar soem" ${ }^{17}$. A partir daí teve lugar uma feroz luta partidária, a qual só terminou quando a "incessa cobiça" do Infante foi plenamente satisfeita.

9 Nas Cortes de Torres Novas [1438], as quais tanto serviram para os procuradores dos estados reconhecerem e prestarem obediência solene ao novo monarca, como para 
aclarar a questão política da regência, viria a ser encontrada uma solução duunviral, que consistia na partilha da regência pelo Infante D. Pedro e D. Leonor ${ }^{18}$. Segundo a Carta de Crença, o recurso a esta solução de partilha foi unicamente para satisfazer a cobiça de D. Pedro ${ }^{19}$. Tal solução, porém, acabou por fracassar por duas razões: (1) D. Leonor não terá sido eficaz no despacho, muito devido ao facto de estar grávida de Joana e aquele trabalho ser laborioso; (2) terá havido descoordenação entre ela e o cunhado, talvez porque as antigas inimizades entre o pai de D. Leonor de Aragão e o sogro do Infante, ambos pretendentes ao trono de Aragão em que, por fim, o primeiro acabou por reinar, não tivessem sido esquecidas ${ }^{20}$. Estando D. Leonor, por assim dizer, sob vigilância da faç̧ão contrária, tal fraqueza não passou despercebida aos partidários de D. Pedro, que não perderam a oportunidade de a criticar e acusar de inaptidão; parecia-lhes que estava aí a prova de que a rainha carecia de personalidade para o cargo. Por isso, vive-se um ambiente revolucionário em Lisboa ${ }^{21}$, por isso D. Pedro rompeu o contrato de regência com D. Leonor e o conflito acerca da regência do reino permaneceu.

Para o dirimir (melhor, para ser consumada a entrega do poder unicamente a Pedro), foram marcadas as Cortes de Lisboa [1439]. A forma excessiva como D. Pedro aí se apresentou: à frente do seu exército ducal (parte do qual dispensou à entrada de Lisboa), para intimidar e desmoralizar os adversários ${ }^{22}$, levou mais tarde os vencedores de Alfarrobeira, na Carta de Crença, a afirmar, com ou sem razão, que nas Cortes de Lisboa ele, ambicioso como era, assaltou o poder:

"iuntou gentes darmas ${ }^{23} \mathrm{e}$ uejo assj poderoso com ellas as cortes [...] que os grandes, com reçeo, e os pequenos, com medo, lhe nom ousascem nem podescem contradizer o que ligeiramente acabou; porque alguns, pello recebido, outros, por hi prometidos beneficios, inclinados, e mujtos por auitar majores escandalos e conhecendo que o seu contradizer nom prestaria, lhe outroguarão todos, ascj a desuairadas fins, o regimento de nossos rrejnos com a tjtoria" ${ }^{24}$.

Por conseguinte, a solução aí encontrada passou pela entrega dos dois institutos: o da tutoria do reino e o da tutoria do rei, ao Infante D. Pedro in solido, quer por ser reconhecido como a pessoa mais capaz, quer pelo respeito à hierarquia familiar dos príncipes de Avis, quer ainda pela aversão que havia no reino ao governo de uma mulher e para mais estrangeira. No apoio recebido nessas cortes, D. Pedro contou sempre com o auxílio dos procuradores dos municípios; também o irmão D. João se revelou um incondicional partidário seu em toda a conjuntura. Como a solução encontrada nas Cortes de Lisboa fosse definitiva e não agradasse à rainha e partidários, o exército real moveulhes dura e excessiva luta armada [Almeirim, Crato...] ${ }^{25}$ com a finalidade de a expulsar do país e, sem oposição, D. Pedro pudesse governar in solido, o que viria a acontecer.

\section{2.}

No fundo temos dois partidos - como assevera Martim de Albuquerque ${ }^{26}$ - , um encabeçado por D. Leonor e o outro por D. Pedro, advogando cada um sua teoria políticojurídica: uma, por assim dizer, de cariz popular, que contestou a força do testamento de D. Duarte, alegando que a sucessão da coroa estabelecida pelos reis em testamento não tinha validade e que, em caso de extinção da dinastia, pertencia às cortes a eleição do rei ${ }^{27}$, tal como tinha ocorrido com a eleição de D. João I nas Cortes de Coimbra; outra, de cariz nobre, que defendia o cumprimento integral do testamento de D. Duarte e, por isso, a outorga do regimento e da tutela do rei menor unicamente a D. Leonor. Além de duas teorias político-jurídicas e de dois cabeças de partido que familiarmente eram cunhados, 
também temos duas questões vistas a posteriori: uma de direito privado: tutela e curatela do rei menor, e outra de direito público: tutela do reino ou regência.

Cada partido fixa-se nos argumentos mais fortes e apresenta-os como melhores. D. Leonor e os seus partidários escudam-se num único e imponente argumento que julgam inatacável: que a rainha viúva é a contemplada no testamento, o qual "concordaua com as leis imperiaes, que outorguarão as titorias dos filhos as viuuas e onestas madres, e com os foros dEspanha e antiguas vsanças e ordenações, praticadas em nossos rrejnos". Esta forma de argumentar, por recorrer ao argumento jurídico, revela que por trás de quem a defende há juristas, mas não sabemos quem são. D. Pedro e os seus partidários, em que pontificam os juristas Diogo Afonso Mangancha e Jean Jouffroy, defendem: (1) que em caso de extinção da dinastia, pertence às cortes a eleição do regente; (2) que o filho secundogénito de D. João I não podia ser excluído da regência até porque se morressem os dois filhos varões de D. Duarte seria ele o rei; (3) e que D. Pedro é a pessoa mais capaz, tanto pela nobreza intelectual como pelo facto de ser homem e, por isso, poder comandar o exército em caso de guerra.

Vejamos cada uma das posições em particular. A primeira questão que se nos coloca é a seguinte: testamento do rei ou cortes na escolha do regente? A rainha viúva e os seus partidários, entre os quais se contam membros da alta nobreza e juristas anónimos, fixam-se exclusivamente neste único argumento, que consideram inatacável sob o ponto de vista jurídico: ela é a única contemplada no testamento do falecido rei e isso é concordante com o direito imperial, o direito hispânico e o direito nacional; e que D. Leonor não pode ser desprovida das duas tutelas "sem manifesta injuria e offensa sua", isto é, sem haver razões penais para a poder privar desse benefício. Além disso, argumentam que, quando o testamento foi revelado, todos o aceitaram sem contestação e juraram fazê-lo cumprir: "prometido e yurado de ter e manter o testamento do dito senhor rrey"28. Mais ainda: nas Cortes de Torres Novas, o testamento foi de novo examinado pelos juristas e de novo foi declarado legal:

"E, sendo os principaes prelados, fidalguos e pouos aiuntados em cortes, foy uisto e examinado o dito testamento; e porque, segundo as forças e clausulas delle, nom podião tolher aa dita senhora minha madre a nossa titoria com o regimento de nossos rrejnos sem manifesta injuria e offensa sua, foy determinado, em as ditas cortes, com acordo de meus tjos, que a dita senhora rrajnha fosse nossa titor" ${ }^{29}$.

Para mais, excluem a possibilidade de que D. Pedro possa partilhar o regimento do reino por não ser contemplado no testamento e acham que as cortes não têm poder para dirimir o conflito, nem há tradição em se imiscuírem nos assuntos da regência. No fundo, a questão principal radica na legalidade do testamento de D. Duarte. Não é de estranhar que este rei, pouco antes da sua morte por peste, tenha tomado precauções no seu testamento acerca da sua sucessão, já que quase todos os reis até ao seu tempo tomaram iguais providências, contemplando uns a sucessão e outros, além da sucessão, a situação da regência. Mas comecemos pelo princípio, já que a posse da coroa tem um longo historial e é oportuno referi-lo.

Entre os visigodos da península, a posse da coroa concretizava-se por eleição geral entre magnates e sacerdotes, por rebelião, ou o rei nomeava o seu sucessor. 0 princípio electivo (que muito mais tarde foi posto em prática em Portugal, nas Cortes de Coimbra de 1385) foi sancionado pelos Concílios de Toledo e era o preferido da nobreza que se opunha ao princípio da hereditariedade ${ }^{30}$. Na Reconquista, a transmissão da coroa foi quase sempre de pais a filhos, ainda que o princípio eletivo não lhe seja estranho. No entanto, a 
hereditariedade prevaleceu no costume, porque os reinos da Península principiaram por ser considerados património dos monarcas, razão pela qual alguns reis dividiram o reino pelos filhos ${ }^{31}$. Aliás, foi tal divisão que proporcionou a Portugal a separação do reino de Castela e de Leão e, portanto, a sua independência.

Quando Portugal se tornou independente pela separação do reino de Castela e de Leão, a hereditariedade em linha direta estava já consagrada por longo uso mantendo-se, passando o trono de pais para filhos ${ }^{32}$. No entanto, o princípio da hereditariedade não era um direito escrito pelo que não podia ainda ter raízes profundas ${ }^{33} \mathrm{e}$, por conseguinte, podia ser questionado, como veio a ser.

Observando o testamento dos primeiros monarcas, Sancho I, Afonso II e Sancho II, onde se estabelece a sucessão da coroa, constata-se que quem herda o trono é o filho primogénito da mulher legítima e a sua descendência; depois os outros filhos do testador pela ordem de nascimento; na falta de herdeiro masculino, são chamadas à sucessão as filhas legítimas pela mesma ordem; não havendo, são chamados os irmãos do rei pela ordem do nascimento (foi assim que $O$ Bolonhês herdou o trono); depois os filhos ou filhas do irmão que reinar (foi assim que D. Dinis herdou o trono); não havendo, a sucessão regressa à linha colateral. É, pois, esta a ordem que se institui em Portugal e Castela: a hereditariedade na linha de sucessão, sem que haja oposição à sucessão na linha feminina, se a masculina faltar (contrariamente à Lei sálica, vigente em França). "A hereditariedade nos fins do século XIV, conclui Gama Barros ${ }^{34}$, era a única doutrina que se reputava jurídica e que tinha voga". D. Afonso II e Sancho II também contemplaram no seu testamento a possibilidade de $\mathrm{o}[\mathrm{a}]$ herdeiro[a] da coroa não ter chegado à maioridade; nesse caso, ditam vagamente, que o[a] herdeiro[a] menor e o reino fiquem em poder dos vassalos até que o sucessor tenha róbora; não surge aqui a possibilidade de a rainha ser a regente, como no testamento de D. Duarte.

Com a morte de D. Fernando [Outubro de 1383], só sobrevive a filha Beatriz, casada com D. Juan I de Castela, e havia o perigo de união das duas coroas. Ficou como regente do reino a rainha viúva, usando de toda a jurisdição e senhorio, mas foi de curta duração porque representava a sujeição à coroa de Castela e a perda da independência. Por isso, o amor da independência reagiu contra o jugo estranho, e o Mestre de Avis, dirigindo o movimento nacional, assumiu o governo do reino em Dezembro de 1383, por eleição do povo de Lisboa, com o título de defensor, que conservou até ser aclamado rei nas Cortes de Coimbra de $1385^{35}$. Argumentaram que, não havendo ninguém que pudesse invocar legitimamente o direito de sucessão, o trono foi declarado vago. Assim sendo, os três estados exerceram a soberania, elegendo o Mestre de Avis, mas não estabelecem disposição alguma quanto à sucessão futura ${ }^{36}$.

D. João I, no seu testamento, declara sucessor o seu filho D. Duarte, primogénito, ou a sua descendência por linha direta; depois os outros filhos seus segundo a ordem de nascimento [Pedro, Henrique, ...], precisamente como tinham feito os reis da Dinastia de Borgonha. D. Duarte, quando já estava atacado de febres mortais, declarou herdeiro seu filho Afonso, mas, por não ter róbora, instituiu como tutora do reino e do rei menor a rainha D. Leonor, sua mulher. Mas pouco depois de ter iniciado funções, as disposições testamentárias foram contestadas e impugnadas, o que não deixa de ser espantoso porque nunca antes o tinham sido, sobretudo pelas razões que os contestatários invocavam: D. Leonor é mulher, é estrangeira, não tem personalidade para o cargo, há três irmãos do rei falecido que têm uma palavra a dizer... Segundo a Carta de Crença, isso foi devido às intrigas de D. Pedro e de seus partidários e não a razões de direito ou de tradição. No 
fundo, o que D. Pedro e os procuradores dos concelhos procuraram fazer foi o mesmo que fora feito em 1385. A recordação desse feito, que conduzira ao período mais extraordinário da história de Portugal, estava ainda bem presente na mente de todos (nacionais e estrangeiros), como J. Jouffroy recorda várias vezes e com nostalgia ${ }^{37}$. Todavia, as situações não são bem a mesma coisa porque se em 1385 há extinção da coroa, o trono fica vago e há risco de perda de independência, em 1449 não se verifica o mesmo.

3.

21 Ao procederem desta forma os reis (i.e., ao pronunciarem-se em testamento acerca da sucessão ou da regência, tal como D. Duarte fez), eles têm em vista a Partida Segunda t. 15, 1. 3 - teoria da patrimonalidade e o instituto da tutela testamentária em geral como figurava no direito romano -, que afirma, dado ser habitual o conflito acerca das tutelas do reino e do rei menor, estabelece-se como lei geral que, no caso de haver testamento ou indicações, que as tutelas fossem dadas à(s) pessoa(s) indicada(s) pelo rei; se não houver, que o(s) tutor(es) fosse(m) escolhido(s) em cortes:

“TíTULO 15: Cuál debe ser el pueblo en guardar al rey de sus hijos

Ley 3: "Ocurre muchas veces que cuando el rey muere, queda niño el hijo mayor que ha de heredar, y los mayores del reino contienden sobre quién lo guardará hasta que sea de edad; y de esto nacen muchos males. Y por ello los sabios antiguos de España, que consideraron todas las cosas muy lentamente y las supieron guardar, por quitar todos estos males que hemos dicho establecieron que cuando el rey fuese niño, si el padre hubiese dejado hombres señalados que le guardasen mandándolo por palabra o por carta, que aquellos hubiesen la guarda de él, y que el rey lo hubiese mandado; mas si el rey finado de esto no hubiese hecho mandamiento ninguno, entonces débense juntar allí donde el rey fuere todos los mayores del reino, así como los prelados y los ricos-hombres y otros hombres buenos y honrados de las villas; y desde que fueren adjuntados, deben jurar sobre los santos Evangelios que anden primeramente en servicio de Dios y en honra y en guarda del señor que tengan y en pro comunal de la tierra y del reino; y según esto, que escojan tales hombres en cuyo poder lo metan, que lo guarden bien y lealmente" ${ }^{38}$.

Tal lei que regula a regência do reino não figura no direito pátrio português. Figura, no entanto, a disposição de que os "padres podem dar tetores, e curadores a seus filhos em testamento", que foi acolhida pelo direito pátrio no tempo de D. João I - como afirma Martim de Albuquerque ${ }^{39}$-, desembargada em cortes gerais e introduzida mais tarde nas Ordenaçôes Afonsinas, liv. 4, t. 85 §7: "Segundo direito os Padres podem dar tutores, e curadores a seus filhos em testamentos... que honde o Padre leixar com quem seu filho viva, e com quem more, ou officio que aja, que assy se cumpra, poendo pena a quem o contrairo fezer" ${ }^{\prime 4}$.

As Ordenações Afonsinas liv. 4, t. 82 também distinguem os três tipos de tutores que a tutela admite $^{41}$ : (1) tutor testamenteiro: os tutores que são deixados pelos pais em testamento e devem ser tidos por bem escolhidos; (2) quando não há testamento, ou indicações em testamento, que seja tutor do órfão o parente mais chegado [tutor lidimo]; (3) quando não há testamento, ou indicações em testamento, ou não há parente chegado, ou se há não pode ou não quer ser, que o juiz do lugar dê ao órfão um homem bom [tutor dativo].

Ora, no caso de Afonso V, há testamento e tutor testamenteiro nomeado pelo rei: é D. Leonor, mãe, e é ela que tem de assumir a tutela do rei à luz da lei. E segundo a mesma lei (O.A. liv. 4, t. 83 \$1), o tutor que o pai escolher será tido como bem escolhido, e a justiça não deverá interferir com a escolha. De igual forma, a justiça não poderá retirar ao tutor 
testamenteiro a tutoria do órfão até que ele atinja a maioridade, excepto se o tutor administrar mal a tutoria ou os bens do tutor (O.A. liv. 4, t. $83 \S 3$ ), tal como os partidários de D. Leonor asseveram ${ }^{42}$.

Porém, uma coisa é a tutela particular, acerca da qual não parece haver dúvida, e outra coisa é a tutela pública do reino. Se D. Leonor também pode assumir a tutela do reino, é outra questão e bem mais difícil de dirimir do que a tutela privada. Contudo, certo é que a vontade do testador D. Duarte e a dos seus juristas era a de que D. Leonor herdasse as duas tutelas - a do rei e a do reino. Na base do seu desejo, do rei e dos seus juristas, talvez estivesse a conviç̧ão de que:

(i) se a mulher, à luz da legislação nacional, não pode ser afastada da sucessão, também não deverá ser afastada da regência do reino;

(ii) ao D. Leonor ser tutora do rei, devia ser igualmente tutora do reino por na Península se considerar, desde o início, que o património do rei é o próprio reino;

(iii) tal como nas tutelas privadas o pupilo herda os bens dos pais, assim na tutela pública o pupilo real herda o reino, que é o seu património ${ }^{43}$.

É um argumento poderoso a favor da legalidade das cláusulas testamentárias do testamento de D. Duarte e, por conseguinte, da legitimidade de D. Leonor; e será a principal razão que explica porque D. Leonor e partidários pugnarão pela regência in solido e porque, em Lisboa, aceitaram contrariados a partilha da regência com o Infante.

\section{4.}

30 Apesar de a lei ser clara, apesar de as instruções deixadas por D. Duarte acerca da sucessão e da tutoria do filho varão terem pleno enquadramento dentro da tradição da casa real portuguesa, do direito comum, do peninsular e das ordenações do reino, "o suprimento da menoridade régia não tardaria a ser posto em crise" ${ }^{44}$ pelos partidários do duque de Coimbra e juristas pró-D. Pedro. As primeiras vozes do descontentamento são atribuídas pela Crónica de D. Afonso $V$ às pessoas anónimas e numerosas da capital, partidárias do duque de Coimbra: "agora pellas praças se solta, que ElRey nosso Senhor, vosso Marido, que Santa Gloria aja, vos nam podia leixar este cargo de reger", cujo argumento é que pertencia às cortes a escolha: "cá este poder demleger Regedor do Reino era somente ao Reino, e aos tres Estados dele resservado" ${ }^{45}$.

Depois virão os juristas pró-Infante com a sua bateria de argumentos, os quais tanto retomam o argumento das Cortes, que foi posto em prática em 1385, mas que não é bem o mesmo, como advogam novos argumentos de vária ordem. 0 primeiro deles foi o Doutor Diogo Afonso Mangancha, ligado ao conselho e desembargo de D. Duarte e apoiante do duque de Coimbra, a quem representou nas Cortes de 1446, na passagem do poder a D. Afonso V; o segundo foi Jean Jouffroy, deão de Vergy, referendário papal, conselheiro de Filipe, o Bom, e embaixador experimentado, tendo sido o cabeça da pequena embaixada borguinhã que D. Isabel de Portugal enviou em 1449-1450, à corte de D. Afonso V, defender a memória do duque de Coimbra e a de seus filhos infamados e espoliados dos bens ${ }^{46}$. Ambos eram juristas in utroque iure e famosos pelas suas bibliotecas particulares, mas enquanto a do português não sobreviveu, a do borguinhão ainda hoje se conserva praticamente intacta! 
Jouffroy, ainda que não negue que a mulher possa assumir as tutelas do reino e do rei, argumenta aos vencedores de Alfarrobeira que a tutela deixada por D. Duarte a D. Leonor é inválida por razões de ordem legal e que nos reinos em que excepcionalmente acontece não são constituídos direitos. Em primeiro lugar, são várias as leis gerais e regulae iuris que excluem as mulheres de todos os cargos civis ou públicos: "As mulheres foram afastadas de todos os cargos civis ou públicos. Por isso, nem podem ser juízes, nem exercer a magistratura, nem requerer judicialmente, nem intervir a favor de alguém, nem ser procuradores" ${ }^{47}$; e também foram excluídas das tutelas por ser um cargo masculino: "Às mulheres não podem ser dadas tutores, porque isso é um cargo masculino, salvo se elas fizerem ao governador um pedido especial para terem a tutela dos filhos" ${ }^{\prime 4}$.

É certo que em determinadas situações (tutela privada) é lícito que a mãe execute a tutela; também é lícito que o testador possa prescrever que a tutela seja regida com o conselho da mãe, mas não é a regra geral, nem tem aplicação no instituto da tutela dos reis. A regra geral, verificada em muitos reinos e corroborada pelas leis imperiais, é que a tutela dos filhos confiada em testamento do pai à mãe é nula: "Segundo o nosso direito, declara-se que a tutela dos filhos comuns, confiada em testamento do pai à mãe, seja nula; e se o governador da província, caído em erro, tiver decretado a vontade do pai, que o sucessor não siga a determinação do governador por as nossas leis não a admitirem" ${ }^{49}$. E é essa a regra que deve ser observada na tutela dos reis - continua Jean Jouffroy, abordando o instituto da tutela do reino, o qual diferencia das tutelas particulares: que o rei não passe o poder para a rainha, até porque, como assevera Gregório Magno nos seus Morais, "O costume da vida de outros tempos determinou que as mulheres não obtenham em herança a administração dos reinos, porque a direção dos reinos necessita do que é forte e menospreza o que é fraco, elege o bem preparado e repele o que é inconstante" ${ }^{50}$.

É certo, continua o orador, que nalguns reinos as mulheres têm o direito de sucessão e dirigem a administração (i. e., são rainhas), mas, além de casos excepcionais, não são constituídos direitos: "Não são constituídos direitos nos casos em que, eventualmente, possam ter acontecido num ou noutro caso" ${ }^{51}$. Além disso, convém distinguir nas tutelas do reino dois graus de direito: o da mulher que, não havendo filhos varões, sobe ao trono por direito de sucessão (mulher herdeira; de autoridade maior por provir de si próprio e que não se verifica no caso de D. Leonor) e o direito da mulher que o administra como regente (mulher regente; mais fraco por provir de outrem, como é o caso de D. Leonor) ${ }^{52}$.

Apesar de toda a série de argumentos extraídos do "bom" direito, não ficamos impressionados com o jurista da Borgonha por sabermos as transformações que o direito justinianeu sofreu na sua adaptação ao direito pátrio, como já vimos anteriormente. Por isso, o que conta - é essa a nossa opinião -, é a legislação nacional, pouco depois transformada em Ordenações Afonsinas, quer tenha sido bem ou mal adaptada pelos juristas da corte; e o direito imperial, direito canónico e as glosas de Acúrsio e de Bártolo não passavam de direito subsidiário neste tempo. Por isso, a legalidade do testamento de $\mathrm{D}$. Duarte e da ascensão de D. Leonor à regência permanecem firmes. Jouffroy sabe disso, por isso tem necessidade de recorrer a novos argumentos para destronar D. Leonor do estado de legalidade e dar razão a D. Pedro. Se conseguir, livrará o antigo regente do crime de lesa-majestade e os seus filhos da infamação em que incorreram por culpa paterna; e atrás da comutação da pena, virá a devolução dos bens copiosos, há pouco confiscados.

D. Pedro - assevera o embaixador borguinhão - não podia ser excluído da partilha do poder, devendo, por isso, ter sido contemplado no testamento de D. Duarte, por várias razões. O direito comum permite constituir como herdeiro um estranho; também é 
possível privar da herança um irmão, desde que não se institua uma indigna pessoa, todavia os reis têm estatuto especial, por não poderem no seu testamento (ao contrário das tutelas particulares) privar da sucessão do reino os que descendem de linha paterna ${ }^{53}$. E como o que é válido para a tutela testamentária é válido para a sucessão, pois são institutos inseparáveis (é a unidade dos institutos sucessórios e da tutela) ${ }^{54}$, D. Pedro, como filho secundogénito de D. João I e, depois da morte de D. Duarte, filho mais velho, nem podia ser privado da tutela do rei menor, nem da sucessão do reino (em caso de morte de D. Duarte sem filhos ou dos filhos de D. Duarte: Afonso e Fernando) por ele ser o legítimo tutor ${ }^{55}$. Estes institutos só a ele, como agnado (parente pela linha masculina) mais próximo, podiam ser confiados e deles não podia ser privado por D. Duarte em testamento. Por conseguinte, D. Pedro poderia estar confiante que a tutela do reino lhe seria entregue por direito próprio. Como ele conhecia este direito, reivindicou-o com alguma veemência, quer apresentando-se nas Cortes de Lisboa com o seu exército ducal; quer, depois destas Cortes, movendo dura luta à rainha e partidários, empecilhos, com a finalidade de os expulsar do país.

De novo o orador da Borgonha recorreu ao direito justinianeu e sem contemplar as transformações que ele sofreu no momento em que foi adaptado bem ou mal para o direito pátrio e que os conselheiros de D. Afonso V lhe lembram. Daí a sua animosidade contra o direito pátrio, a que chama "não direito, mas a dissolução do direito"56. Num tempo de evolução do quadro legislativo e em que o direito justinianeu (também chamado comum ou imperial) vinha a ser substituído pela legislação e ordenações nacionais, talvez Jouffroy tenha sido a primeira pessoa a insurgir-se contra as Ordenações Afonsinas, publicadas havia muito pouco tempo, precisamente no final da regência de D. Pedro. Assim sendo, a questão da legalidade de D. Leonor permanece.

o partido de D. Pedro tem em grande consideração a escolha do regente em Cortes, não só porque isso lhe é favorável, mas também porque estava na memória de todos as felizes Cortes de Coimbra de 1385, em que o Mestre de Avis foi alçado rei e que daria origem, quiçá, ao melhor período da história de Portugal. Jean Jouffroy sabe disso, eis porque não se esquece de explorar este campo, preocupado como está em ver atendidos na corte de Portugal os rogos de D. Isabel da Borgonha. Daí a questão: qual o poder das cortes na escolha do(s) tutor(es) do reino e do rei menor.

O partido de D. Leonor argumenta que as cortes não têm poder nenhum, o qual reside unicamente no testamento do rei; por seu lado, o partido do Infante, fortemente apoiado na mediação popular, argumenta - comparando esta situação com a que ocorreu em 1383, mas as duas situações não são iguais - que em caso de extinção da dinastia pertence às cortes a escolha do monarca ${ }^{57}$. Esta é naturalmente também a opinião do embaixador da Borgonha, empenhado como está em defender na corte de Évora, onde foi recebido em 1449 , os interesses de D. Isabel. A governação do reino e os bens do reino - argumenta Jean Jouffroy - são de todos os cidadãos, e estes deliberaram em Cortes que tais cargos (quer a tutela do reino, quer a tutela do rei) conviessem a D. Pedro, e o que a maior parte do reino decidir pelo direito subsiste:

“Ora, se se diz que a governação do reino e os bens do reino são de toda a gente, é por isso que, segundo Inocêncio, no cânon Quarto, título De Iureiurando [liber Extra.], o que a maior parte do reino decidir pelo direito subsiste ${ }^{58}$. Importa lembrar que os legados de todas as cidades e de todos os concelhos, que todos os nobres de teus reinos e todos os prelados intercederam para que o infante Pedro assumisse a tutela da tua majestade. Negar isto não podem os teus conselheiros, porque se podem 
mostrar as cartas e as assinaturas deles nelas firmadas. Além disso, eu poderia mostrar o consentimento da tua ilustrísssima mãe, somente o qual bastaria" ${ }^{2}$. destinos nacionais, é um bom argumento, até por, à distância de muitos anos, conhecermos a feliz escolha em cortes do Mestre de Avis para rei. Além disso, já em 1450, quando o embaixador borguinhão esteve na corte de D. Afonso V, em Évora, era evidente que tinha sido uma boa escolha, como se depreende das palavras elogiosas que tece ao fundador da dinastia de Avis. Mas a questão de fundo permanece: infelizmente a eleição do regente em cortes pela maioria dos membros presentes não está contemplada no direito pátrio, antes estivesse! Não há lei do reino que reserve às Cortes a escolha do sucessor ou do regente como na monarquia visigótica.

\section{5.}

da questão que se coloca: "A direcção dos reinos necessita do que é forte e menospreza o que é fraco, elege o bem preparado e repele o que é inconstante" ${ }^{62}$. Esta citação a partir dos Moralia de Gregório Magno foi apresentada pelo embaixador à Corte como argumento e significa que a regência atribuída a $D$. Pedro não pode ser acusada porque ele é mais capaz do que a cunhada para o cargo de regente do reino, aliás, ele é o melhor de todos. 0 tema da maior competência de D. Pedro quando comparada com as capacidades de D. Leonor é fácil de dirimir, tal a distância que os separa, e é até das coisas mais certas nesta conjuntura. Ainda que haja na questão da competência alguma subjectividade, e toda a gente seja capaz de fornecer exemplos de pessoas competentes que desiludiram e de candidatos medianos que surpreenderam, a verdade é que o vulto de D. Pedro, quando comparado, dá outras garantias que D. Leonor não pode dar. É claramente dito pelo orador da Borgonha e pelos historiadores que dos dois um é incomparavelmente melhor do que o outro e toda a gente sabe quem é. É aqui que as qualidades dos dois cabeças de partido mais discrepam ${ }^{63}$.

Acerca das capacidades políticas de D. Leonor, pouco sabemos. A Crónica de D. Afonso V ${ }^{64}$ diz que era "muyto honesta, virtuosa, prudente, devota e muyto amiga da vyda e honra d'elRey seu Marido", mas isso não é um atestado de competência política e, mesmo assim, pode nem sequer ser verdade por fazer parte de uma tópica "a persona", como muitas vezes acontece nas Crónicas. Ana Maria Rodrigues, que estudou a pessoa de D. Leonor, fala da educação nobre da rainha ${ }^{65}$, mas que de forma alguma é igual à educação política dada aos filhos varões. Além disso, enquanto rainha, pouco contacto teve com a 
administração do reino por D. Duarte ser muito dedicado ao despacho e consagrar-lhe grande parte do dia, reservando para D. Leonor uma participação muito restrita ${ }^{66}$. Além disso, ainda que exercesse influência sobre $0 \mathrm{rei}^{67}$, não deixa de ser uma figura politicamente apagada e de fraca experiência política, quando comparada, por exemplo, com a condessa D. Teresa.

Já quanto a D. Pedro o caso é diferente, pois conhecemos as suas qualidades políticas, intelectuais e militares. Basta citar a carta acerca da realeza que ele enviou a D. Duarte, depois de ter sido alevantado rei ${ }^{68}$; ou então a Carta de Bruges $^{69}$ : um extenso memorando de teor político remetida ao irmão Duarte sobre o que deve ser a sua acção governativa, para revelar como o duque de Coimbra nutre paixão pela política e tem uma ideia para o país, além de D. Duarte lhe pedir conselhos. Além disso, D. Pedro era pessoa viajada, a ponto de Veiga Simões dizer hiperbolicamente que "partiu um homem medieval e voltou um homem moderno"70; e era pessoa culta, fama que ganhou na tradição cultural como (entre outros méritos) ${ }^{71}$ autor do Livro dos 0 Ofícios $^{72}$, tradutor $^{73}$ e promotor de traduções ${ }^{74}$, facto que levou Rui de Pina a afirmar que era príncipe "bem latinado, e assaz mistyco ${ }^{75} \mathrm{em}$ ciencias e doutrinas de letras, e dado muyto ao estudo"76.

Jean Jouffroy traçou desta forma o seu perfil de estadista e viajante: "Um Infante valente, justo, sério, benéfico, liberal, magnânimo, que espalhou quase por todo o mundo excelentes virtudes" ${ }^{77}$, o qual, em parte, deve ser entendido por ele ser o advogado do Infante na Corte; mas se o louvor está ferido de exagero, está longe da negatividade e dos juízos de desvalor com que a Carta de Crença o trata ao classificá-lo de ambicioso sem limite, de "perigoso traidor" e de se ter locupletado durante a regência. Apesar de as qualidades de D. Pedro, quando comparadas com as de D. Leonor, parecerem superiores o que não quer dizer que ela fosse pior regente do que o Infante -, ainda assim isso não serve de argumento, porque o direito pátrio não contempla a questão da competência. Antes contemplasse, como nas modernas sociedades meritocráticas ou mesmo como nas Cortes de Coimbra de 1385 !

Quanto à questão de género: se uma mulher pode ou não assumir a regência, é claro hoje e comumente aceite, mas não na Idade Média com a mesma clarividência. A citação anterior dos Moralia e muitas outras que poderiam ser feitas revelam os preconceitos "antifeministas" (para usar um conceito que hoje é familiar, mas que não existia na Idade Média) alimentados por via erudita e popular e as reservas colocadas às capacidades femininas. Ainda assim, os testamentos dos reis, como já vimos, não excluem a mulher da sucessão, colocando-a, todavia, depois do homem, e da regência. Entre as limitações da "fragilidade da natureza feminina" ou da "fraqueza do sexo feminino" está a potestas militaris: a inabilidade da mulher para executar serviços militares ou comandar o exército em caso de guerra ${ }^{78}$. Jouffroy lembra isso e é mais um argumento para impressionar, até porque as capacidades militares de D. Pedro eram bem conhecidas: combateu contra os turcos na Hungria, fazendo-se comunicar em latim, e contra os mouros no norte de África.

47 Se ao que fica dito juntarmos a itinerância da corte durante a Idade Média por motivos políticos (os juristas não falam nisso, mas não deixa de ser uma questão pertinente); e o facto de D. Leonor ser mãe de vários filhos, ainda que andasse sempre acompanhada de aias; e ainda a sua má prestação depois das Cortes de Torres Novas, muito devido ao facto de estar grávida, mas que os seus inimigos políticos não desculparam; e, mais do que ser mulher, ser "aquela mulher", que é estrangeira e irmã dos infantes de Aragão e de família rival da de D. Pedro, são tudo desvantagens e formas de enfraquecer a sua posição quando 
comparada com a figura masculina de D. Pedro, príncipe de Avis, aliás, o mais velho depois da morte de D. Duarte. Diogo Afonso de Mangancha, outro jurista que se pronunciou sobre o conflito, destacou sobretudo o mérito da pessoa de D. Pedro, a qual, quando confrontada com a figura débil de D. Leonor, mais se agiganta. Pouco antes do início das Cortes de Lisboa, numa sessão de esclarecimento e de apoio ao Infante na Câmara de Lisboa, foi-lhe pedido uma pública declaração sobre o caso. Depois de ter apontado os erros de o regimento ter sido repartido em Torres Novas, continua a Crónica de D. Afonso $V^{79}$ :

"com determinaçooẽs do Dereito Canonyco e Civel, e com autorydades do Testamento Novo e Velho ${ }^{80}$, e com emxemplos d'estoreas antygas reprovou Regimento público ser dado a molher, perque excludio a Raynha; e com outras de nom menos rezam e autoridade, provou que devia ser dado a homem baram, em que ouvesse as virtudes e calidades, que todas achou com verdade no Yfante Dom Pedro".

Portanto, Afonso Mangancha não nega, como outros membros da fação popular negaram, que, legalmente, a mulher não possa herdar o regimento do reino. Ele sabe que já no passado D. Teresa o herdou (se é que podemos falar desta forma tão ligeira) e como D. Leonor Teles o herdou de facto, ainda que por pouco tempo. O que ele diz é que "não deve" porque há alternativa melhor; perante dois candidatos à regência, eventualmente tão legal um como o outro, D. Pedro é francamente melhor e mais popular, e é o melhor que deve ser escolhido.

Apesar da opinião concordante destes dois juristas, a questão de fundo continua por resolver: D. Pedro é, em abstracto, melhor candidato, é homem, pode comandar o exército, todavia a escolha por competência ou por género (tal como o princípio da maioria referido pelo Deão de Vergy) não está contemplada nas tutorias dos órfãos, mas unicamente quem o testador designar como tutor testamenteiro, o qual é D. Leonor. Assim sendo, a questão da legalidade do testamento do falecido rei permanece, e D. Leonor só poderia ser excluída das duas tutelas, como asseveram os juristas seus partidários na Carta de Crença, se desistisse da regência voluntariamente, ou se fosse declarada incapaz, ou ainda por "manifesta injuria e offensa sua" de um crime. Os partidários de D. Pedro, no seu afã de triunfar, ainda tentaram a via da incapacidade quando a acusaram, depois das Cortes de Torres Novas, de inapta pela má prestação e fracasso no despacho, ao não cumprir atempadamente (ao contrário do coregente D. Pedro) as suas funções, esquecendo a sua desvantagem em relação ao cunhado por ser mãe de vários filhos de tenra idade e por estar grávida de Joana.

6.

Portanto, a legalidade parece estar do lado de D. Leonor, tendo em conta a legislação nacional, que é essa a que conta, pois o direito romano, canónico e as glosas de Acúrsio e de Bártolo, que os juristas defendem, são direito subsidiário naquele tempo. Daí as palavras de Manuel Heleno: “A verdade porém é que, como a legislação nada dispunha sobre regências e os costumes nenhuma resolução segura autorizavam, como não havia exemplos das cortes se imiscuírem em tais assuntos, a vontade de D. Duarte, não tendo nenhuma norma a limitá-la, devia ser cumprida. A legalidade estava portanto do lado da Rainha e dos seus partidários"82; e noutra parte assevera que D. Pedro se apoderou revolucionariamente do poder ${ }^{83}$. 
51 Não obstante a aparente legalidade da rainha viúva, a verdade é que acaba por ser destronada pouco a pouco de todos os poderes, incluindo o da tutoria do rei; e como se isso não bastasse, foi-lhe montada apertada vigilância no seu paço. Por fim, sentindo-se prisioneira na própria casa, encetou a fuga para Almeirim e Crato, onde foi perseguida por D. Pedro com força excessiva e forçada ao exílio em Castela, que era o que se pretendia. Perde o confronto partidário em favor do cunhado Pedro, não porque carecesse de razão, mas porque é a parte mais fraca da contenda.

52 Acerca das implicações futuras que originou a luta pela tutoria de D. Afonso V, afirma Martim de Albuquerque ${ }^{84}$ : o caso de Afonso V representa, a diversos títulos, um marco na história das regências em Portugal. Não apenas pelas sequelas políticas que teria, mas porque deu origem a que se equacionassem os grandes problemas do instituto: direito do povo ou do rei na designação do regente do sucessor menor?; capacidade ou incapacidade das mulheres para exercerem a regência? A estes dois problemas, acrescentou-se então um outro: o termo da regência ou o início da maioridade do monarca. Finalmente, tomouse nessa altura consciência, embora nem sempre de forma clara, de que existem duas situações distintas durante o período da incapacidade do monarca: uma respeitante à sua pessoa (tutela regis), outra relativa ao reino (tutela regni), ou seja, como hoje diríamos, uma de direito privado, de direito público a outra.

\section{Conclusão}

53 Não havendo uma lei da sucessão e da regência do reino, mas apenas tradições, não é fácil dizer a quem assiste a razão no confronto havido entre D. Leonor e D. Pedro, cabeças de partido, pela posse das tutelas do reino e do rei na menoridade de D. Afonso V. Como se trata de uma questão de direito privado (tutela do rei) e de direito público (tutela do reino), convém atender nos aspectos jurídicos da questão. Se se atender ao direito pátrio que estava a ser compilado e culminou no tempo da regência de D. Pedro na publicação das Ordenações Afonsinas, à tradição da casa real portuguesa contemplada nos testamentos dos reis, às regências anteriores, especialmente as femininas, a ideia que se tira é que D. Leonor tem a primazia na regência e só no caso de ela desistir das duas tutorias ou de perder o direito por manifesta culpa pessoal é que o candidato a seguir, D. Pedro, pode assumir funções. É essa a ideia que parece estar latente no testamento de D. Duarte e que, com toda a certeza, tem por trás a mão de juristas da corte; é também essa a opinião dos partidários de rainha viúva, em que pontificam elementos da nobreza senhorial.

Pelo contrário, dois outros juristas, os únicos que se pronunciaram publicamente sobre a questão de forma oral e escrita: Afonso Mangancha, brevemente, e Jean Jouffroy, de forma bem desenvolvida, advogam a legitimidade de D. Pedro na regência. Apoiam-se no Direito Comum ou Justinianeu e no Direito Canónico, o "bom" direito, e repelem os códigos legislativos nacionais e as transformações e adaptações que o direito imperial tinha sofrido na sua adaptação ao direito pátrio. Em concreto, Jean Jouffroy cita, em primeiro lugar, o Digesto, o Codex e o Decretum de Graciano, mas também as Glosas de Acúrsio, os Conselhos de Bártolo, as Decretais de Gregório IX, o livro Sexto de Inocêncio IV, a Authentica, os Moralia in Job de Gregório Magno, a Clementina... ${ }^{85}$ Todavia, o direito imperial era cada vez mais direito subsidiário devido à emergência do corpus legislativo nacional que estava a ser compilado e que pouco depois seria publicado com o nome de Ordenações Afonsinas. Por isso, é lícito pensar que o parecer destes juristas, que advogavam a legitimidade de D. Pedro na regência, tem de ser visto mais por serem seus partidários e 
torcerem para o lado do partido que estão a defender do que pela força e atualidade dos seus argumentos.

Onde falha a diplomacia, entra a força, e aí os argumentos estão do lado de D. Pedro porque se apresentou em Lisboa com o seu exército para dissuadir os inimigos e tem mais gente a seu lado, sobretudo os procuradores dos concelhos e vilas do reino e ainda o povo de Lisboa, que decidiram a questão a seu favor, tal como tinha sido feito em 1385, nas Cortes de Coimbra. Por isso vai vencer e ser regente in solido, mas com a vitória também assinou a sua sentença de morte que lhe estava reservada para o dia em que abandonasse a regência.

\section{BIBLIOGRAFIA}

Fontes impressas

CORPUS IURIS Civilis. Ed. Theod. Mommsen-Paulus Krüger. Vol. I. 18ª ed. Berlim, 1965.

CORPUS IURIS Civilis. Ed. Paulus Krüger. Vol. II. 13ª ed. Berlim, 1963.

CORPUS IURIS Civilis. Ed. R. Schöll-G. Kroll. Vol. III. 8ª ed. Berlim, 1963.

FRIEDBERG, E. - Corpus Iuris Canonici. Pars prior: Decretum magistri Gratiani. Leipzig, 1879 [reimpr. Graz, 1959].

FRIEDBERG, E. - Corpus Iuris Canonici. Pars secunda: Decretalium collectiones. Leipzig, 1881 [reimpr. Graz, 1959].

INFANTE D. PEDRO; [colab.] Frei João Verba - Livro da vertuosa benfeytoria. Ed. crítica, introdução e notas de Adelino de Almeida Calado. Coimbra: Biblioteca Geral da Universidade de Coimbra, 1994. LAS SIETE partidas del Sabio Rey D. Alonso, extractadas por D. Ignacio Velasco Peres. Madrid, 1843. LIVRO DOS OFÍCIOS de Marco Tullio Ciceram o qual tornou em linguagem o Infante D. Pedro. Ed. Joseph M. Piel. Coimbra: Acta Universitatis Conimbrigensis, 1948.

MONUMENTA HENRICINA. Ed. de Dias Dinis. Vol. X. Coimbra, 1969, doc. 49, pp. 71-79.

ORDENAÇÕES AFONSINAS. 4 vols. Lisboa: Fundação Calouste Gulbenkian, 1984.

PINA, Rui de - “Cronica do Senhor Rey D. Affonso V". in Crónicas de Rui de Pina, introdução e revisão de M. Lopes de Almeida. Porto: Lello \& Irmãos Editores, 1977, pp. 577-881.

Estudos

PINA, Rui de - “As regências na História do Direito Público e das ideias políticas em Portugal”. in Estudos de cultura portuguesa. Vol. 1. Lisboa: Imprensa Nacional Casa da Moeda, 1984, pp. 11-33.

PINA, Rui de - "Politica, moral e direito na construção do conceito de estado em Portugal". in Estudos de cultura portuguesa. Vol 1. Lisboa: Imprensa Nacional Casa da Moeda, 1984, pp. 125-248.

PINA, Rui de - "O Infante D. Pedro e as Ordenações Afonsinas". in Estudos de cultura portuguesa. 3 vols. Imprensa Nacional Casa da Moeda, 1993, pp. 125-248.

PINA, Rui de - A consciência nacional portuguesa. Verbo, 2016. 
PINA, Rui de - ; ALBUQUERQUE, Ruy de - História do Direito Português. 2 vols. Lisboa: Pedro Ferreira, 1999.

AMARAL, Luís Carlos; BARROCA, Mário Jorge - A condessa-rainha Teresa. Maia: Círculo de Leitores, 2012.

BARROS, Henrique da Gama - História da Administração Pública em Portugal nos séculos XII a XV. Vol. 3. Lisboa: Sá da Costa, 1946.

CAMPOS, Isabel Maria Garcia - Leonor Teles, uma mulher no poder? Vol. I. Porto: Faculdade de Letras da Universidade do Porto, 2008. Dissertação de Mestrado em História Medieval.

Disponível em: repositorio.ul.pt/bitstream/10451/1751/1/21996_ulfl062047_tm.pdf

DUARTE, Luís Miguel - D. Duarte. Rio de Mouro: Círculo de Leitores, 2005.

FREITAS, Judite Gonçalves de - “D. Leonor de Aragão: imagens de contestação e de poder”. in TOSCANO, Ana M.; GODSLAND, Chelley - Percepção e representações da Mulher transgressora no mundo Luso-Hispânico. Mulheres Más. Vol. I, Cap. I. Porto: Edições Universidade Fernando Pessoa, 2004, pp. 103-122.

Disponível em: https://www.academia.edu/14253995/

GOMES, Saul A. - D. Afonso V. Rio de Mouro: Círculo de Leitores, 2006.

GONÇALVES, José Júlio - O Infante D. Pedro, as sete partidas e a génese dos Descobrimentos. Lisboa: Agência Geral do Ultramar, 1955.

GUTIÉRREZ-ALVIZ, Faustino - Diccionario de derecho romano. Madrid: Editorial Reus, 1995.

HELENO, Manuel - Subsídios para o estudo da regência de D. Pedro, duque de Coimbra. Lisboa. 1933.

MARQUES, Alfredo Pinheiro - Vida e obra do Infante D. Pedro. Lisboa: Gradiva Publicações, 1996.

MERÊA, M. Paulo - Estudos de História de Portugal. Lisboa: Imprensa Nacional Casa da Moeda, 2006.

MORENO, Humberto Baquero - A Batalha de Alfarrobeira. Antecedentes e significado histórico.

Lourenço Marques, 1973.

PINHo, Sebastião - “O Infante D. Pedro e a "escola” de tradutores da corte de Avis”. Biblos 69 (1993), pp. 129-153.

RAMOS, Manuel - "O impacto de Alfarrobeira nas relações com o ducado da Borgonha”. História. Revista da FLUP, IV Série, vol. 5 (2015), pp. 23-36.

RAMOS, Manuel - Orationes de Jean Jouffroy em favor do Infante D. Pedro (1449-1450) - Retórica e Humanismo Cívico. Porto, Faculdade de Letras, 2007.

RODRIGUES, Ana Maria S. A. - As tristes rainhas. Leonor de Aragão e Isabel de Coimbra. Círculo de Leitores, 2012.

SÁ, Artur Moreira de - A “Carta de Bruges” do Infante D. Pedro”. Coimbra, 1952 (Separata de Biblos , vol. XXVIII).

SARAIVA, António José - O crepúsculo da Idade Média em Portugal. Lisboa: Gradiva, 1993.

SILVA, J. Espinosa Gomes da - História do Direito Português. Fontes de Direito. Lisboa: Fundação Calouste Gulbenkian, 1991.

ULLMANN, Walter - Historia del pensamiento político en la Edad Media. Barcelona: Editorial Ariel, 1983. 


\section{NOTAS}

1. PINA, Rui de - "Cronica do Senhor Rey D. Affonso V". in Crónicas de Rui de Pina, introdução e revisão de M. Lopes de Almeida. Porto: Lello \& Irmãos Editores, 1977, cap. 86, p. 696: "ydade de XIV anos (...) qualquer Pryncepe Real deve aver ynteira posse e administaçam de seu Reyno e Senhoryo". Veja-se cap. 2, pp. 588-590. A propósito, afirma BARROS, Henrique da Gama - História da Administração Pública em Portugal nos séculos XII a XV, vol. 3. Lisboa: Sá da Costa, 1946, p. 313, que no reino de Portugal, durante este período, a maioridade dos príncipes não estava determinada por nenhum preceito especial, contudo o costume mais seguido indicava a idade de 14 anos.

2. Como assevera o Codex $2,45,2$, ao menor em idade podia ser concedida a dispensa da idade ("v eniam aetatis") e ver a maioridade antecipada, mas nunca antes dos 20 anos. Veja-se RAMOS, Manuel - Orationes de Jean Jouffroy em favor do Infante D. Pedro (1449-1450) - Retórica e Humanismo Cívico. Porto, Faculdade de Letras, 2007, pp. 203-206; ALBUQUERQUE, M. - "As regências na História do Direito Público e das ideias políticas em Portugal". Estudos de cultura portuguesa. Lisboa: Imprensa Nacional Casa da Moeda, 1984, p. 31; GUTIÉRREZ-ALVIZ, Faustino - Diccionario de derecho romano. Madrid: Editorial Reus, 1995, p. 695.

3. Ver AMARAL, Luís Carlos; BARROCA, Mário Jorge - A condessa-rainha Teresa. Maia: Círculo de Leitores, 2012, p. 169 e ss. Se é duvidoso que D. Teresa fosse uma regente de plenos poderes e de facto, num mundo eminentemente masculino, era pelo menos uma mulher de grande poder.

4. O papel político da rainha D. Leonor Teles, antes e durante a regência, mereceu o estudo de CAMPOS, Isabel Maria Garcia - Leonor Teles, uma mulher no poder? Vol. I. Porto: Faculdade de Letras da Universidade do Porto, 2008. Dissertação de Mestrado em História Medieval. Disponível em: repositorio.ul.pt/bitstream/10451/1751/1/21996_ulfl062047_tm.pdf.

5. Aconteceu isso com D. Sancho I, que foi associado ao trono na parte final da vida do pai, depois do desastre de Badajoz (1169-1185). Também D. Duarte foi associado ao trono por seu pai (1412-1433), exercendo uma espécie de co-regência. BARROS, Henrique da Gama - História da Administração Pública, p. 309, fala também de D. Dinis associado ao trono pelo pai Afonso III; e de D. Pedro associado ao trono pelo pai Afonso IV em 1355.

6. BARROS, Henrique da Gama - História da Administração Pública, p. 316, refere que quando D. Afonso IV foi ao Salado não deixou regente, mas D. João I fê-lo quando foi a Ceuta, deixando o Mestre de Avis; e D. Afonso V fê-lo por diversas vezes durante as suas ausências em África, Castela e França.

7. Veja-se TORGAL, L. Reis - Ideologia política e teoria do Estado na Restauração. Vol. I. Coimbra: Biblioteca Geral da Universidade, 1981, pp. 231-233.

8. Ver GOMES, Saul A. - D. Afonso V. Rio de Mouro: Círculo de Leitores, 2006, p. 42.

9. MONUMENTA HENRICINA. Ed. de Dias Dinis. Vol. X. Coimbra, 1969, doc. 49, pp. 71-79; veja-se também RAMOS, Manuel - Orationes de Jean Jouffroy, pp. 93-101. Citaremos a primeira destas obras por ser mais acessível.

10. MONUMENTA HENRICINA, vol. X, doc. 49, p. 71. Ver ainda Crónica de D. Duarte, cap. 44, p. 575 e Afonso V, cap. 3, p. 590.

11. PINA, Rui de - "Cronica do Senhor Rey D. Affonso V", cap. II, p. 590.

12. Veja-se DUARTE, Luís Miguel - D. Duarte. Rio de Mouro: Círculo de Leitores, 2005, p. 264.

13. MONUMENTA HENRICINA, vol. X, doc. 49 , p. 71.

14. PINA, Rui de - "Cronica do Senhor Rey D. Affonso V", cap. 3, pp. 590-591; veja-se GOMES, Saul A. -

D. Afonso V, p. 45.

15. PINA, Rui de - "Cronica do Senhor Rey D. Affonso V", cap. II, p. 590.

16. PINA, Rui de - “Cronica do Senhor Rey D. Affonso V”, cap. 3, p. 591; veja-se cap. 14.

17. MONUMENTA HENRICINA, vol. X, doc. 49 , p. 72. 
18. D. Leonor ficava com a tutoria do filho; D. Pedro com a organização militar e o comando do exército, e ambos repartiriam as relações externas, a concessão de tenças, privilégios e doações e o regimento da praça de Ceuta (GOMES, Saul A. - D. Afonso V, pp. 47-48).

19. MONUMENTA HENRICINA, vol. X, doc. 49, pp. 72-73.

20. Veja-se MORENO, Humberto Baquero - A Batalha de Alfarrobeira, p. 26 ss. Tal inimizade remonta ao difícil processo sucessório de Martinho, o Humano, rei de Aragão, que culminou no compromisso de Caspe, reunião que designou para o trono Fernando de Antequera, pai de Leonor e dos infantes de Aragão. O conde de Urgel, D. Jaime (sogro de D. Pedro), derrotado, não tendo aceitado a decisão, liderou uma revolta militar contra o vencedor que havia de o levar, tempos depois, à morte. Daí nasceu uma inimizade profunda entre a esposa de D. Pedro (e ele próprio) e D. Leonor, mulher de D. Duarte (Veja-se DUARTE, Luís Miguel - D. Duarte, p. 125).

21. MORENO, Humberto Baquero - A Batalha de Alfarrobeira, p. 30 ss.

22. MORENO, Humberto Baquero - A Batalha de Alfarrobeira, p. 51 ss.

23. Veio às Cortes de Lisboa acompanhado por mil e oitocentos cavaleiros e dois mil e seiscentos peões. Porém, dispensou a maioria à sua chegada a Lisboa (MORENO Baquero A Batalha de Alfarrobeira. Antecedentes e significado histórico. Lourenço Marques, 1973, pp. 51-54; PINA, Rui de - "Cronica do Senhor Rey D. Affonso V", cap. 45.

24. MONUMENTA HENRICINA, vol. X, doc. 49, p. 73.

25. MORENO, Humberto Baquero - A Batalha de Alfarrobeira, p. 67 ss.

26. ALBUQUERQUE, Martim de - "As regências na História do Direito Público e das ideias políticas em Portugal”, Estudos de cultura portuguesa, p. 16 e ss.

27. PINA, Rui de - “Cronica do Senhor Rey D. Affonso V”, cap. 3, p. 591; veja-se cap. 14.

28. MONUMENTA HENRICINA, vol. $\mathrm{X}$, doc. 49, p. 72.

29. MONUMENTA HENRICINA, vol. $\mathrm{X}$, doc. 49, pp. 72-73.

30. Ver BARROS, Henrique da Gama - História da Administração Pública, p. 289 ss.

31. BARROS, Henrique da Gama - História da Administração Pública, p. 299.

32. BARROS, Henrique da Gama - História da Administração Pública, p. 300.

33. BARROS, Henrique da Gama - História da Administração Pública, p. 301.

34. BARROS, Henrique da Gama - História da Administração Pública, p. 306.

35. BARROS, Henrique da Gama - História da Administração Pública, p. 316.

36. BARROS, Henrique da Gama - História da Administração Pública, p. 306.

37. "D. João, por cuja bravura este teu reino existe"; "rei D. João, o melhor de todos os reis" ( RAMOS, Manuel - Orationes de Jean Jouffroy, pp. 179 e 215).

38. LAS SIETE partidas del Sabio Rey D. Alonso, extractadas por D. Ignacio Velasco Peres. Madrid, 1843, pp. 154-155.

39. ALBUQUERQUE, Martim de - "As regências na História do Direito...", p. 16 e ss.

40. ORDENAÇÕES AFONSINAS. 4 vols. Lisboa: Fundação Calouste Gulbenkian, 1984, p. 315.

41. ORDENAÇÕES AFONSINAS, pp. 305-306.

42. ORDENAÇÕES AFONSINAS, pp. 306-307.

43. J. Jouffroy não concordará e dirá que uma coisa é a tutela privada e outra a tutela pública, como veremos.

44. ALBUQUERQUE, Martim de - Estudos de cultura portuguesa, 1 vol, p. 16.

45. PINA, Rui de - "Cronica do Senhor Rey D. Affonso V", cap. 3, p. 591; veja-se cap. 14.

46. Ver RAMOS, Manuel - "O impacto de Alfarrobeira nas relações com o ducado da Borgonha". História. Revista da FLUP, IV Série, vol. 5 (2015), pp. 23-36.

47. Digesto 50,17,2 - Das diversas regras do direito antigo: "Foeminae ab omnibus officiis ciuilibus uel publicis remotae sunt et ideo nec iudices esse possunt, nec magistratum gerere, nec postulare, nec pro alio interuenire, nec procuratores existere". 
48. Digesto 26,1,18 - Das tutelas: "Foeminae tututores dari non possunt, quia id munus masculorum est, nisi a principe filiorum tutelam specialiter postulent".

49. Digesto 26,2,26 - Da tutela testamentária: "Iure nostro tutela communium liberorum matri, testamento patris, frustra mandatur: nec, si prouinciae Praeses imperitia lapsus patris uoluntatem sequendam decreuerit, successor eius sententiam, quam leges nostrae non admittunt, recte sequetur".

50. Gregorius Magnus, Moralia in Job, lib. XXXV, cap. XIV.

51. Digesto 1,3,4 - Das leis, das decisões do senado e do costume antigo: "Ex his, quae forte uno aliquo casu accidere possunt, iura non constituuntur".

52. Digesto 40,5,33,1.

53. Diz Inocêncio IV no cân. Grandi, tit. De supplemento negligentia prael., liv. Sexto (Sext. 1,8,2).

54. Digesto 50,17,73; Digesto 26,2,3.

55. Acresce o facto de ele ter sido a primeira pessoa a ser escolhida por D. Duarte para a curatela do rei menor, como já foi referido.

56. RAMOS, Manuel - Orationes de Jean Jouffroy, p. 217.

57. PINA, Rui de - "Cronica do Senhor Rey D. Affonso V", cap. 3, p. 591; veja-se cap. 14.

58. Ideia próxima de algumas regulae iuris: Ulpiano, Digesto 50.17.160.1: “Refertur ad uniuersos, quod publice fit per maiorem partem" (Atribui-se a todos o que de maneira pública se faz pela maioria); Escévola, Digesto 50.1.19: "Quod maior pars curiae efficit, pro eo habetur, ac si omnes egerit" (O que fez a maior parte da cúria tem-se como feito por todos); "Maior pars trahit minorem" (A parte maior leva consigo a menor); Paulus, Digesto 50.17.110pr.: "In eo quod plus sit, semper inest et minus" (No que é mais sempre está compreendido também o menos).

59. RAMOS, Manuel - Orationes de Jean Jouffroy em favor do Infante D. Pedro (1449-1450), p. 203.

60. MORENO, Humberto Baquero - A Batalha de Alfarrobeira, p. 55 e ss.

61. BARROS, Henrique da Gama - História da Administração Pública, p. 101.

62. Gregorius Magnus, Moralia in Job, lib. XXXV, cap. XIV.

63. Veja-se FREITAS, Judite Gonçalves de - "D. Leonor de Aragão: imagens de contestação e de poder". in TOSCANO, Ana M.; GODSLAND, Chelley (ed.) - Percepção e representações da Mulher transgressora no mundo Luso-Hispânico. Mulheres Más. Porto: Edições Universidade Fernando Pessoa, 2004, vol. I, cap. I, p. 111 e ss. Disponível em: https://www.academia.edu/14253995/

64. PINA, Rui de - "Cronica do Senhor Rey D. Affonso V", cap. 2, p. 590.

65. RODRIGUES, Ana Maria S. A. - As tristes rainhas. Leonor de Aragão e Isabel de Coimbra. Círculo de Leitores, 2012, pp. 40-42.

66. RODRIGUES, Ana Maria S. A. - As tristes rainhas, p. 118 e ss.

67. RODRIGUES, Ana Maria S. A. - As tristes rainhas, p. 121.

68. PINA, Rui de - “Cronica do Senhor Rey D. Duarte”. in Crónicas de Rui de Pina. Introd. e revisão de M. Lopes de Almeida. Porto: Lello \& Irmãos Editores, 1977, cap. IV, pp. 495-498.

69. SÁ, Artur Moreira de - “A carta de Bruges do Infante D. Pedro". Biblos 28 (1952), pp. 33-34.

70. De acordo com MARQUES, Alfredo Pinheiro - Vida e obra do Infante D. Pedro. Lisboa: Gradiva Publicações, 1996, p. 37.

71. Na sua ânsia de reformar a justiça, fez concluir as Ordenações Afonsinas, código legislativo iniciado no reinado de D. João I, que "representam, essencialmente, obra do Regente D. Pedro" (ALBUQUERQUE, Martim de - "O Infante D. Pedro e as Ordenações Afonsinas". Estudos de cultura portuguesa. Vol. 3. Lisboa: Imprensa Nacional Casa da Moeda, 1993, p. 43). A sua preocupação com as leis e o ensino levou-o a conceber o projecto de uma nova universidade em Coimbra custeada pelas suas rendas e sob a sua protecção. Foi criada em 1443, em nome de D. Afonso V, mas com a morte prematura em Alfarrobeira e a sua memória danada, o projecto não teve continuação (SARAIVA, António José - 0 
crepúsculo da Idade Média em Portugal. Lisboa: Gradiva, 1993, p. 128; PIEL, Joseph M. (ed.) LIVRO DOS OFÍCIOS de Marco Tullio Ciceram o qual tornou em linguagem o Infante D. Pedro. Ed. Joseph M. Piel. Coimbra: Acta Universitatis Conimbrigensis, 1948, p. XX.

72. Compôs, em 1418, em parceria com Frei João Verba, o Livro da virtuosa bemfeitoria (conservase), que tem como ponto de partida o De beneficiis de Séneca.

73. Além de autor, diz-se que traduziu o De re militari ou Epitome rei militaris de Flávio Vegécio Renato (desaparecido), e o De regimine principum de Egídio Romano (desaparecido) ( PINHO, Sebastião - "O Infante D. Pedro e a "escola" de tradutores da corte de Avis", Biblos 69 (1993), p. 144). Com o De officiis (Livro dos ofícios) de Cícero (1433-1438), códice latino que havia sido uma oferta "assaz dannos ha" do Infante D. Fernando e que também constava da biblioteca de Condestável D. Pedro (conserva-se), foi o primeiro tradutor de um clássico latino para português. 74. Além de autor e tradutor, D. Pedro foi também promotor de traduções. De facto, em 1442, encomendou a Vasco Fernandes de Lucena "que lhe tornasse em lingoagjem" o De ingenuis moribus et liberalibus studiis de Pier Paolo Vergerio (desaparecido, excepto o prólogo da tradução) ( LIVRO DOS OFÍCIOS, pp. XLVI-XLVII), tratado pedagógico destinado à educação de D. Afonso V; o De senectute (Livro da Velhice), de Cícero (desaparecido, excepto o longo prólogo ou carta de encomenda) (LIVRO DOS OFÍ́CIOS, pp. XLIII-XLVI) e o Panegyricus Traiano Augusto, de Plínio o Jovem (desaparecido, excepto o prólogo ou carta de encomenda) (LIVRO DOS OFÍCIOS, pp. XLI-XLII).

75. I. e., enciclopédico.

76. PINA, Rui de - "Cronica do Senhor Rey D. Affonso V", cap. 125, p. 754.

77. RAMOS, Manuel - Orationes de Jean Jouffroy, p. 215.

78. Que a mulher não comanda o exército é reiterado na paremiografia, por exemplo, o monóstico de Menandro (157 Jäkel): “à mulher a natureza não deu o dom de comandar". Nos paremiógrafos aparece como paradoxo evidente a expressão: "a mulher comanda o exército", ainda que Joana d'Arc tenha fornecido inspiração e direcção militar.

79. PINA, Rui de - "Cronica do Senhor Rey D. Affonso V", cap. 36, pp. 624-625; veja-se cap. 46, pp. 638-639.

80. Por exemplo, a tradição misógina de S. Paulo e a esposa submetida ao marido; também há escritos patrísticos. Por exemplo, os profetas e reis de Israel são homens, já que a herança do reino faz-se pela via agnatícia (masculina). A mulher também está excluída do sacerdócio.

81. MONUMENTA HENRICINA, vol. X, doc. 49, p. 73.

82. HELENO, Manuel - Subsídios para o estudo da regência de D. Pedro. Lisboa, 1933, p. 17

83. HELENO, Manuel - Subsídios, p. 18.

84. ALBUQUERQUE, Martim de - “As regências na História do Direito...”, p. 23.

85. A lista completa encontra-se em RAMOS, Manuel - Orationes de Jean Jouffroy, pp. 235-250.

\section{RESUMOS}

A questão da regência na menoridade de D. Afonso $V$, em que D. Leonor começou por ser investida no cargo de regente e assumido plenos poderes, mas que posteriormente a sua autoridade foi posta em causa, vindo a perder nas Cortes de Lisboa [1439], em favor de D. Pedro, a tutoria do reino e do rei menor, não é de fácil resolução por não haver uma lei da sucessão na regência. Assim sendo, talvez as pessoas mais autorizadas para se pronunciarem sobre este controverso caso, de entre as muitas que o fizeram, sejam os juristas. Dois deles: Afonso 
Mangancha e Jean Jouffroy, Deão de Vergy, tomaram posições públicas sobre a questão, o primeiro na altura dos acontecimentos, o segundo a posteriori. Ainda que não se conhecessem, as suas opiniões são concordantes e são favoráveis a D. Pedro: a mulher não deve obter a regência. No entanto, quando se trata de indagar a fortaleza e a justeza dos seus argumentos, ficamos desconfiados do seu discurso por sabermos que, como juristas, estavam a favor da parte que representavam ou defendiam e não tanto a favor da verdade ou da equidade. Ainda assim, vale a pena conhecer os argumentos de que cada lado se mune e averiguar acerca da sua robustez.

The question concerning the regency during D. Afonso $\mathrm{V}$ minority is not an easy one to solve. During this period, D. Leonor became the Regent of the country and she was sworn in full powers for the government of the kingdom, but later her authority was questioned and she lost her cause against D. Pedro during the "Cortes de Lisboa" in 1439. The tutorial power over the kingdom and the young king was not an effortless answer to achieve, since there was no Law on the subject of the succession of Regency. Thus the lawyers might become the most accurate authorities to tackle the problem, among the many that actually did so. Two of them: Afonso Mangancha and Jean Jouffroy, dean of Vergy, took a public position on these questions. The former jurist presented his view at the time of the events and the latter a posteriori. Although they had never met, they held similar opinions and they both favoured D. Pedro's intentions: no woman should ever be in charge of the Regency. Nevertheless, when it comes to analysing and evaluating the power and propriety of their arguments, we get suspicious of their speeches for we know that, as lawyers, they were supporting the interests they represented. They were not searching the truth and the equity. Even so, it is worth knowing the arguments of each of them and finding out their strength.

\section{ÍNDICE}

Keywords: Regency during D. Afonso V minority, Afonso Mangancha and Jean Jouffroy, D. Leonor of Aragon, D. Pedro - duke of Coimbra

Palavras-chave: Regência de D. Afonso V, mulher regente, D. Leonor de Aragão, D. Pedro duque de Coimbra, Afonso Mangancha e Jean Jouffroy

\section{AUTOR}

\section{MANUEL FRANCISCO RAMOS}

Universidade do Porto, Faculdade de Letras, Departamento de Estudos Portugueses e Românicos / Instituto de Filosofia, 4150 - 564, Porto, Portugal mramos@letras.up.pt 